\title{
Experiences with Fibre Ropes as Hoist Ropes in Crane Applications
}

\author{
Ilaka Mupende ${ }^{1 *}$, Felix Lukasch ${ }^{2}$, Philipp Tonnier ${ }^{3}$ \\ Liebherr Components Biberach GmbH, Biberach, Germany \\ 1 Head, Research \& Technical Testing \\ 2 Team Leader, Research \& Technical Testing \\ 3 Engineer, Research \& Technical Testing \\ * Correspondence: Ilaka.MupendeDr@liebherr.com
}

Received 18 Oktober 2020; Accepted 19 Oktober 2020; Available online 7 December 2020

(C) 2020 by A. Mupende et al. This is an open access article distributed under the Creative Commons Attribution License (CC-BY 4.0), which permits unrestricted use, distribution, and reproduction in any medium, provided the original work is properly cited.

\begin{abstract}
High strength polymer fibres are opening new fields in regard on their strength to weight ratio. In 2009 Liebherr and Teufelberger started a development partnership to utilise these opportunities and rethink the basics of hoist ropes for cranes: (1) Introduction; (2) The high strength fibre rope soLITE; (3) Load bearing capacity of the rope; (4) Liebherr fibre crane series; (5) Discard criteria.
\end{abstract}

KEYWORDS Liebherr, Teufelberger, fibre rope, fibre cranes, rope, discard criteria, hoist rope, high performance fibre, polymer, high-modulus fibre, running ropes

\section{Introduction}

Liebherr is covering a wide spread field of on- and offshore crane applications. In all hoist drives, the rope weight reduces the load capacity of the whole crane system. When regarding the increase in specific strength of modern polymer materials back in 2009, Liebherr and Teufelberger started a development partnership to bring new materials into hoist ropes. Liebherr presented their result, the new Fibre-Crane Series, on Bauma 2019 and started with the delivery in January 2020.

\section{The high strength fibre rope soLITE}

In 2008 Liebherr was checking new materials regarding their lightweight construction potential for cranes. The idea of using high strength polymer fibres as load bearing structure in hoist ropes raised, to reduce the dead load in crane drives. With the support and the experience of Teufelberger, an Austrian wire and fibre rope specialist, the common goal was faced to bring fibre ropes into crane rope drives around the world. 
The development product was first presented on Bauma 2016. The rope is the result of over 100 rope prototypes with different rope constructions and materials. The outcome of all these tests is a construction with a protecting jacket and a load bearing core.

\section{Requirements for the development of the fibre rope}

- Equivalent break load at the same diameter of a wire rope

- At least the same lifetime performance than wire ropes

- Compact layer build-up to enable multi-layer spooling

- Non-rotating behaviour over the whole load spectrum

- Save discard criteria

- Easy and safe end terminations

- High resistance against environmental and job site influences

\section{Challenges to meet the requirements for the new rope}

The first challenge to meet the requirements was finding an appropriate rope construction to ensure a stable rope profile to provide the basis for multi-layer spooling. The second challenge was to find a simple discard recognition system, comparable to wire ropes. The solution is a special rope jacket design, which is calibrated with its wear resistance, to indicate the residual lifetime of the rope core.

\section{The rope construction}

The construction bases on a comparable design to normal non-rotating (twisted) wire ropes with some specific modifications. The rope is made out of 3 layers with different layer directions to ensure a balanced inner torque throughout the load range of the rope. Inside the rope the strands are covered with special coatings to reduce the inner wear.

This special design provides the unique lifetime performance of the Liebherr fibre rope with an increase in lifetime by up to factor 10 at maximum design load. The very high specific strength of the fibres therefore realizes a weight saving of up to $80 \%$ in comparison to an equivalent wire rope. The rope layers are protected against outer wear and environmental influences by the protective jacket, see Figure $1[1]$.

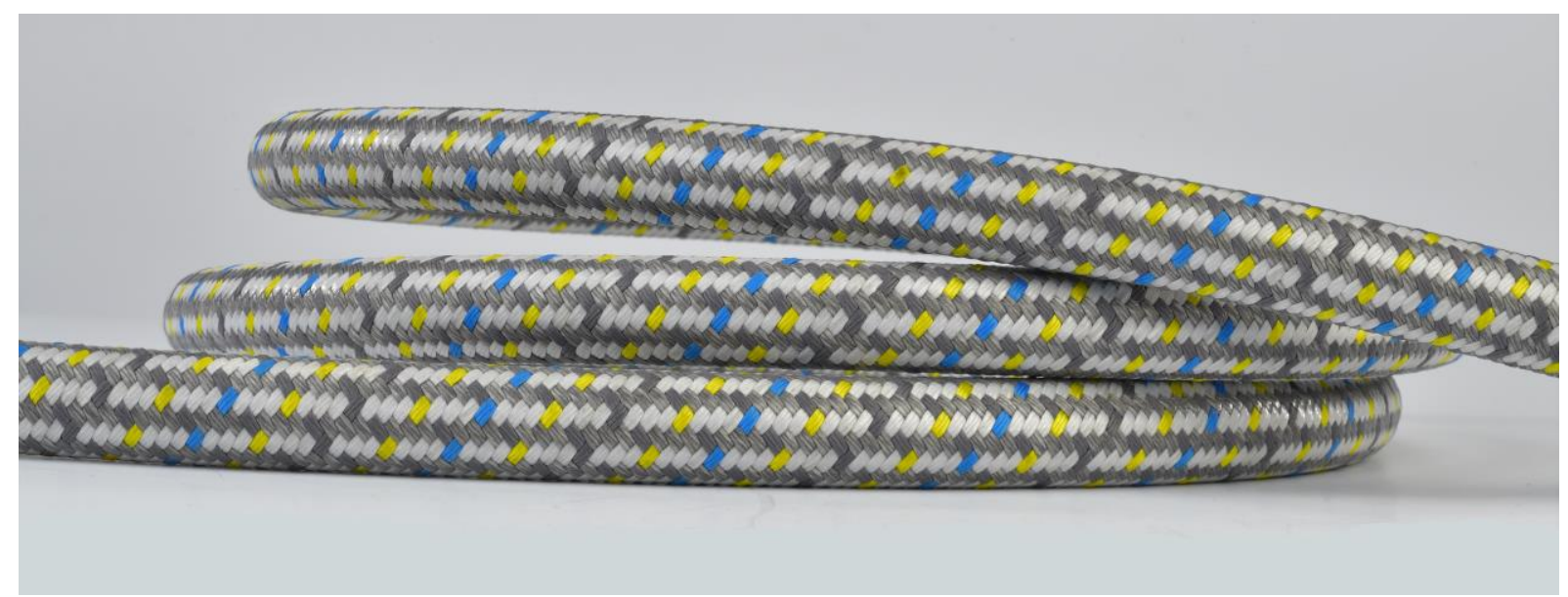

Figure 1: soLITE ${ }^{\circledR}$ fibre rope, developed by Liebherr and Teufelberger. 


\section{Load bearing capacity of the fibre rope}

\section{Load bearing capacity of the developed rope types}

Currently there are two developed rope diameters of soLITE available. The $20 \mathrm{~mm}$ soLITE rope is already in use on tower cranes with $10 \mathrm{t}$ maximum load or $5 \mathrm{t}$ line pull. The $22 \mathrm{~mm}$ soLITE rope is in use for $12 \mathrm{t}$ tower cranes. The comparison between wire and fibre rope is shown in Table 1.

Table 1: Comparison between wire ropes and available soLITE ropes

\begin{tabular}{llll}
\hline Fibre rope diameter & $\begin{array}{l}\text { Minimum breaking load of } \\
\text { the fibre rope }\end{array}$ & $\begin{array}{l}\text { Equivalent wire rope } \\
\text { diameter } \\
\sigma_{\max }=1.770\end{array}$ & $\begin{array}{l}\text { Weight reduction by } \\
\text { using fibre rope }\end{array}$ \\
{$[\mathrm{mm}]$} & {$[\mathrm{kN}]$} & {$[\mathrm{mm}]$} & {$[-\%]$} \\
\hline 20 & 222 & 16 & 75 \\
22 & 294 & 18 & 77 \\
\hline
\end{tabular}

\section{Lifetime determination of the soLITE ropes}

The determination of the rope lifetime was another major challenge for the development of the fibre rope. Standard lifetime tests on ropes are performed on CBOS machines (cyclic bending over sheaves). However, it is difficult to convert the CBOS lifetime onto a normal crane setup. A real crane setup shows influences a CBOS test cannot reproduce like: twist due to fleet angle between sheaves and twist and lateral pressure because of the multi-layer winding on the rope drum.

For fibre ropes the standard rope lifetime determination formulas [5] cannot be used because there is no available parameter set $[6,7,8]$ to use the formulas with up to 30 different influence factors. Liebherr started building up its unique centre for rope and rope drive testing at Liebherr's plant in Biberach in 2010, shown in Figure 2. This test centre enables a rope lifetime determination with nearly all influences in the later use

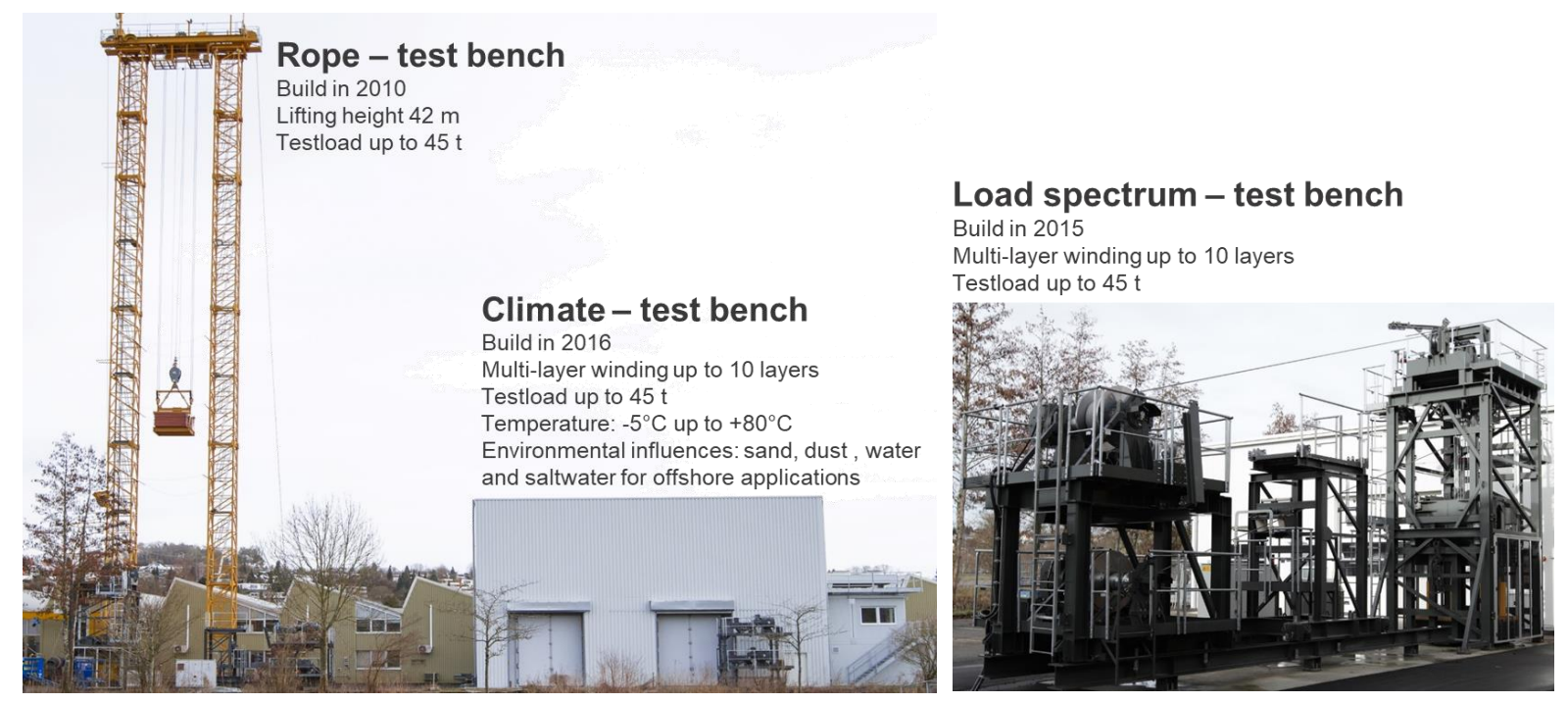

Figure 2: Centre for rope and rope drive testing with the major test benches. 


\section{Rope Lifetime and design choice}

The lifetime of the soLITE fibre rope was determined under different conditions like:

- Different safety factors

- Different operating modes (winding up without load and lowering with load)

- Different environmental conditions like: temperature, humidity, salt atmosphere

When it comes to new materials, it is always necessary to find appropriate constructions. The following Figure 3 shows the long way finding the right material out of different highperformance fibers like LCP (liquid crystalline polymers), different aramids and UHMWPE (Ultra high molecular weight polyethylene).

The appropriate design 2.3 for the Designfreeze and todays series production is the result of an optimized construction and the use of the material properties for innovative production steps.

In a direct comparison at room temperature the lifetime of the fibre rope exceeds the lifetime of a standard wire rope by up to factor 10. Even at the end of the intended maximum operating temperature at $\mathrm{T}=50^{\circ} \mathrm{C}$ the lifetime is higher than conventional wire ropes.

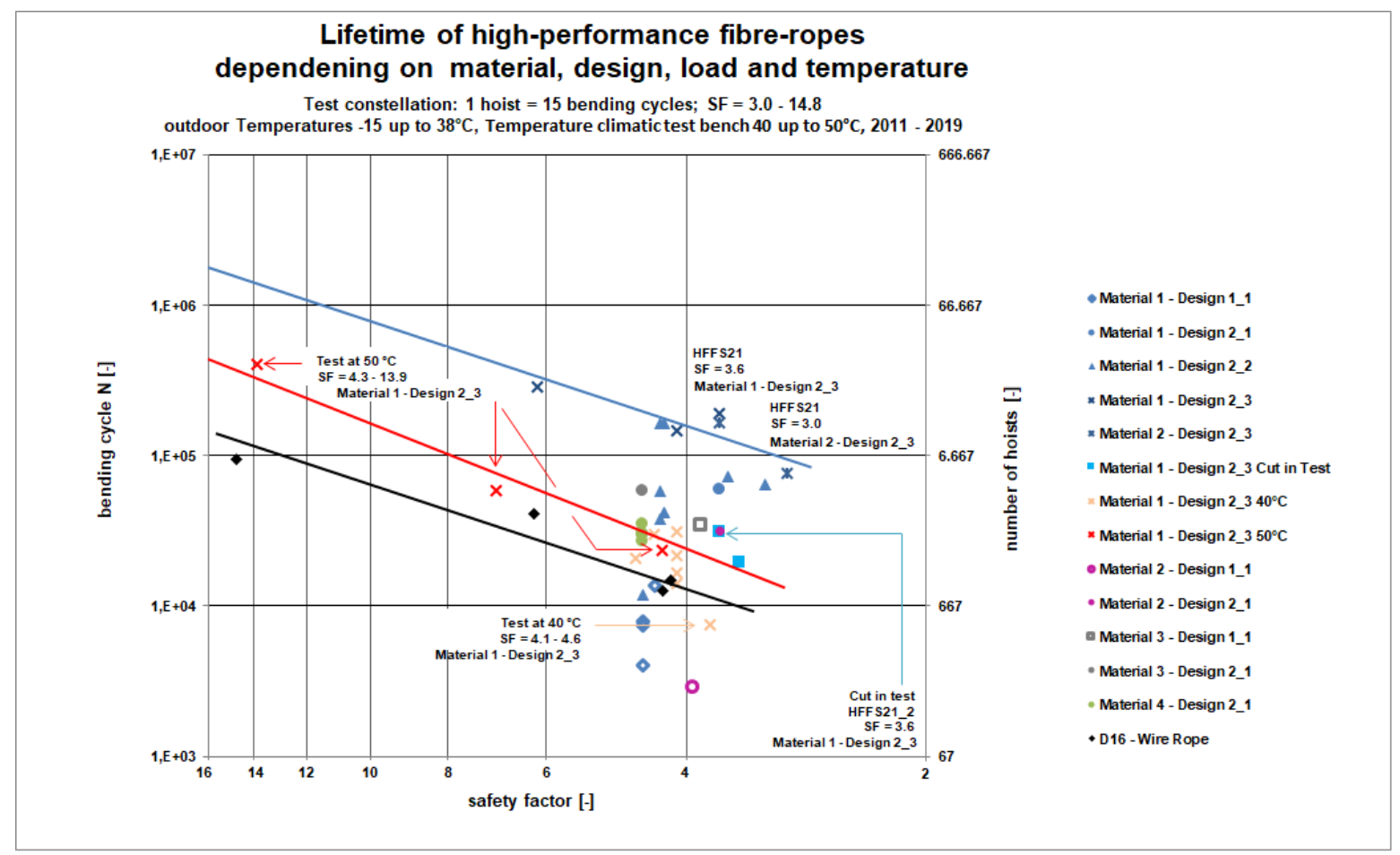

Figure 3: Comparison of rope lifetime results depending on material, design, load and temperature.

\section{Liebherr Fibre Crane Series}

\subsection{Crane design changes for the fibre rope}

In order to use the new fibre rope technology, there are some requirements but also huge benefits for a modern crane system. The design changes of the rope drive system of modern tower cranes 

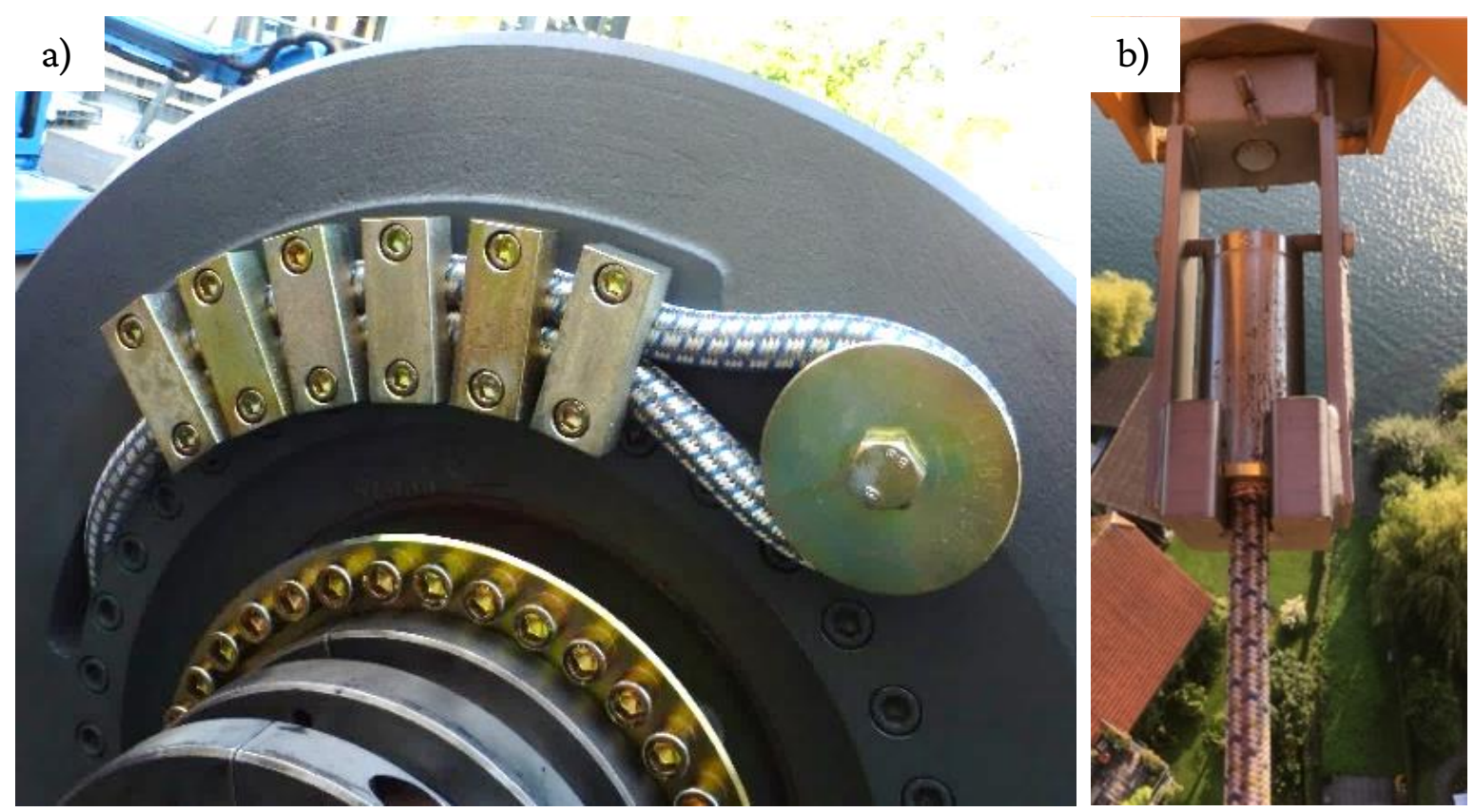

Figure 4: End termination on winch side (a) and on load side (b).

are shown in Figure 4. The low friction coefficient of the fibre rope requires optimized end terminations for the soLITE rope.

The winch termination is designed with a patented system [2], including double clamping and additional enlacement over a sheave. This additional load reduction setup compensates the lower friction coefficient of the soLITE rope. The soLITE socket as the end termination on load side is optimized, to ensure a good load distribution in the rope core. Both end terminations are conform to the standards FEM 5.024 [3] and ISO 23624 [4].

\subsection{Field testing}

Before the start of production in 2020, Liebherr ensured that the new fibre rope fulfils their performance standards for ropes in a wide spread field test study. Liebherr started the field test study in 2016 with up to 18 tower cranes with the intention to ensure the good overall performance of the fibre rope with cranes on costumer sites.

Both available rope diameters 20 and 22 were extensively tested on costumer sites with $10 \mathrm{t}$ and $12 t$ tower cranes before starting series production.

For the occurring incidents during the field test phase, like load hook twists or collisions, corrective actions were developed. The Liebherr fibre cranes were able to prove their high level of performance and the new capabilities of the new fibre rope technology.

\section{Removal of load hook twists}

On tower cranes with fibre and wire ropes, load hook twists can be caused by similar work cycles or induced twists during the run-in phase of the new ropes in the rope drive, see Figure 5 a). 


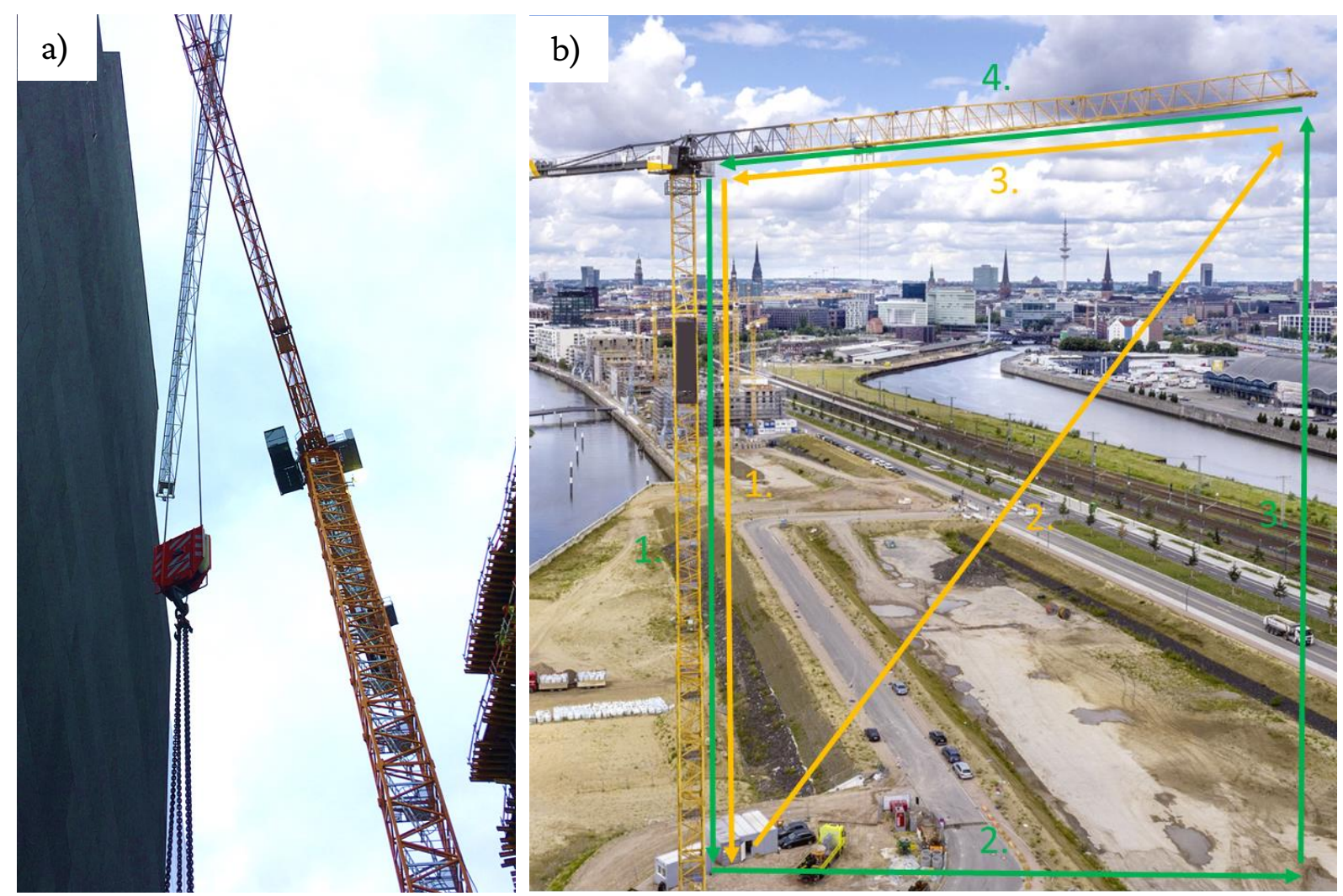

Figure 5: a) 278 EC-B12 Fibre with twisted load hook due similar work cycles over long term, b) twist removal cycle

On fibre cranes the low friction coefficient and the smooth jacket surface of the rope ensures that the rope is not damaged while moving a twisted hook. There are no critical effects, which are known from wire ropes, like catching up or massive wear.

Generally, twisted load hooks should be removed to decrease supplemental wear of the rope jacket. Therefore, the standard removal cycles, see Figure $5 \mathrm{~b}$ ), to transport the local torsion in the rope to the open end with the rotary swivel is used. Because of the very good torque balance of the rope, the torque momentum generated by the twisted fibre rope is lower in direct comparison to steel ropes. To fasten the twist removal process, a certain amount of load helps to increase the torque momentum of the rope and therefore the transport to the rotary swivel.

Currently fibre ropes are used on cranes with $-50 \%$ reduced load hook weight on crane setups up to $115 \mathrm{~m}$ hook heights. This illustrates the good torque balance of the new fibre rope.

\section{Repair solution for damaged ropes}

When working on costumer sites simultaneously with numerous cranes collisions can be an issue due to intersecting work ranges. The following Figure 6 shows the resulting damage of a collision of the rope with the structure of another crane under the following conditions:

- Fibre crane with concrete-casing element $\sim 350 \mathrm{~kg}$

- $2^{\text {nd }}$ crane on site swung in the fibre rope with its boom 

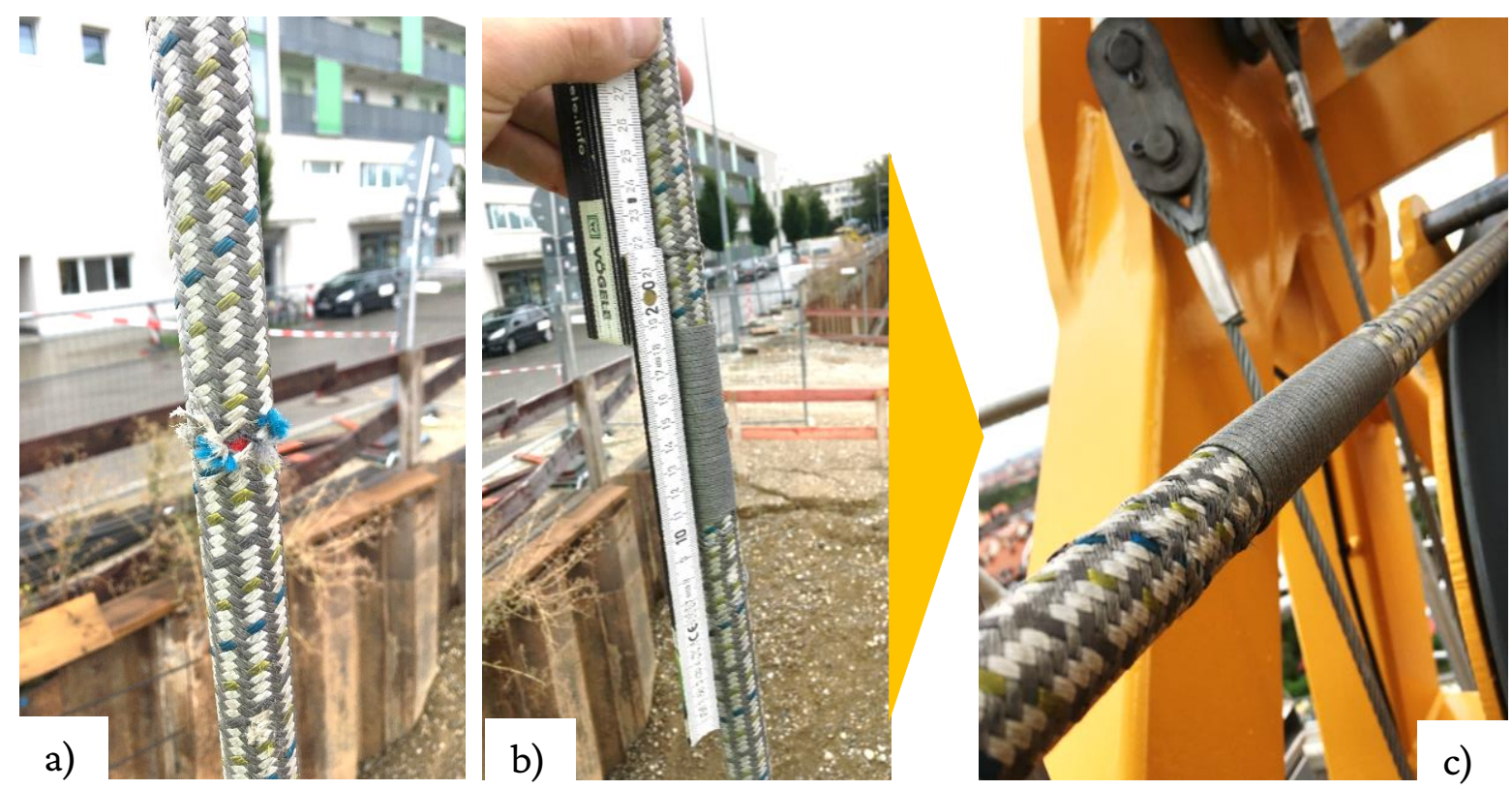

Figure 6: Repair solution b) and c) for the rope jacket in case of jacket damage a)

The rope jacket shows a high level of cut and wear resistance but also indicates damage caused by collisions trough exposing the red colored core. The damage can easily be seen and repaired, if the following conditions are fulfilled:

- No visible damage of the core

- No contamination of the core with dirt and particles

- The damage of the jacket is in the following limits:

Cut circumference is less than $180^{\circ}$ over the circumference

Cut length is less than $50 \mathrm{~mm}$ in rope direction.

- Damage is not a result of the normal wear indication and can be dedicated to a certain event

When the conditions are fulfilled, the repair solution with its special combination of yarn and sewing technique guarantees a long-lasting protection of the load bearing rope core. The endurance of the repair solution is proofed on test cranes, which are running with rope patches for over two years now. On the test benches the patched rope sections are working under full design load over $1 / 2$ of the fatigue lifetime of the fibre rope.

\subsection{Liebherr Fibre Cranes}

The benefits of the new lightweight rope were directly used to improve the load performance of the fibre cranes. The main benefits [9] are pointed out in Figure 7. The reduced rope weight by up to $-80 \%$ allows a weight reduction of the crane hook of about $-50 \%$. This weight reduction in the rope drive system allows a direct increase in payload. Additionally, the reduced rope weight eases the handling process during the crane build up process and saves energy because of the reduced dead load in the rope drive. The fact that the fibre rope does not need any lubrication and the increase in rope lifetime by factor 4 is reducing the service downtimes to a minimum. Also, the easy discard system provides a fast and reliable solution to determine the discard status of the rope. 

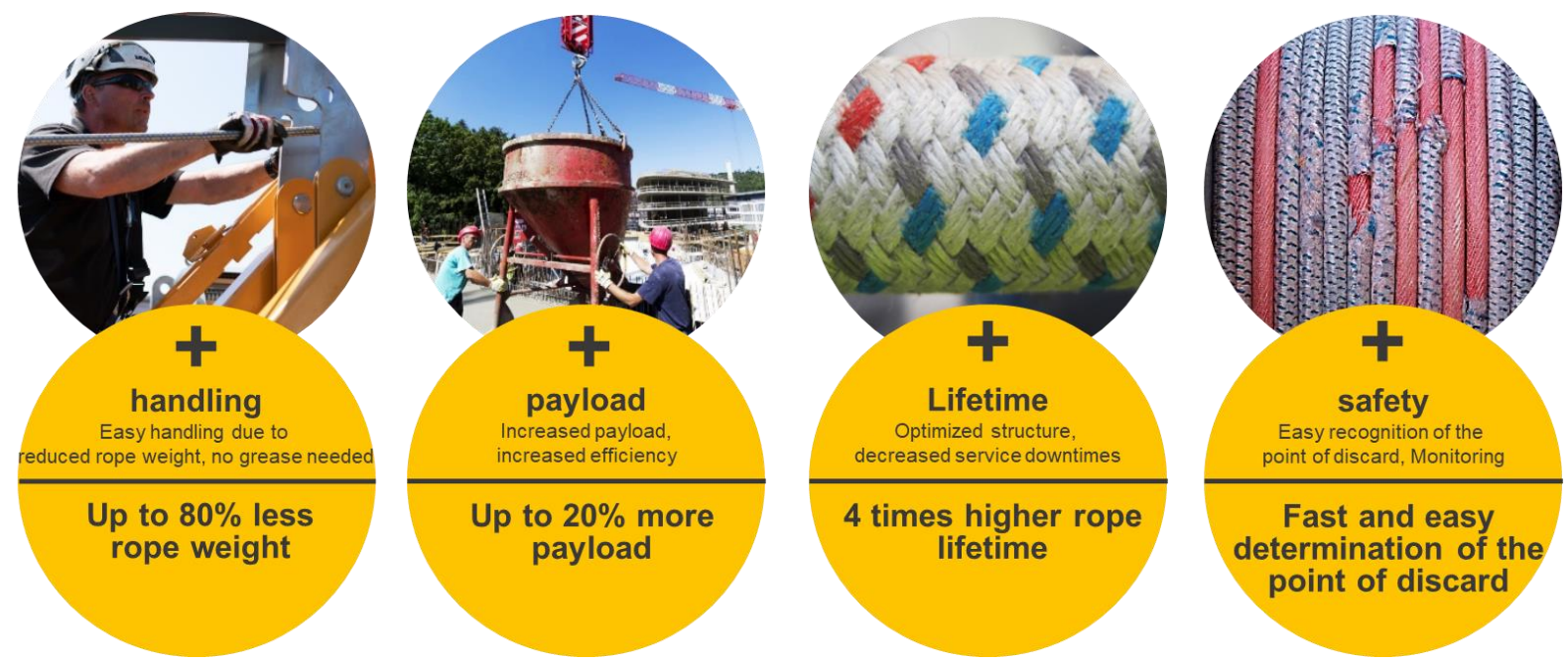

Figure 7: Benefits achieved by the adaption of the wire rope crane to the new fibre rope

Table 2: Comparison between Liebherr flat-top tower cranes with fibre and wire ropes

\begin{tabular}{llllll}
\hline Crane Type & Max. capacity & $\begin{array}{l}\text { Rope diameter } \\
\end{array}$ & $\begin{array}{l}\text { Outreach for } \\
\text { load }\end{array}$ & $\begin{array}{l}\text { Max. load at } \\
\text { outreach }\end{array}$ & $\begin{array}{l}\text { Max. load } \\
\text { equivalent } \\
\text { wire rope crane } \\
{[\mathrm{kg}]}\end{array}$ \\
\hline 240 EC-B 10 Fibre & $10 \mathrm{t}$ & {$[\mathrm{mm}]$} & {$[\mathrm{m}]$} & {$[\mathrm{kg}]$} & 2600 \\
240 EC-B 12 Fibre & $12 \mathrm{t}$ & 20 & 65 & 2850 & 2600 \\
278 EC-B-12 Fibre & $12 \mathrm{t}$ & 22 & 65 & 2750 & 2400 \\
370 EC-B-12 Fibre & $12 \mathrm{t}$ & 22 & 70 & 2850 & 2250 \\
\hline
\end{tabular}

The available tower cranes are achieving the following load increases, in comparison to wire rope cranes, see Table 2.

The throughout positive feedback out of the fibre crane product rollout confirmed the resolution to focus on bigger rope diameters to improve the performance of all crane types.

\section{Discard criteria}

New technologies must meet the existing safety levels of the conventional technologies. The discard recognition system for wire ropes was developed through the last 150 years of industrial use. Standardized methods [10] like counting broken wires are well suited for ropes under high load in multi-layer use. But when it comes to load collectives with high percentage of low loads the wire breaks occur on inner parts of the rope and are no longer visible in the visual inspection of the outside, see Figure 8.

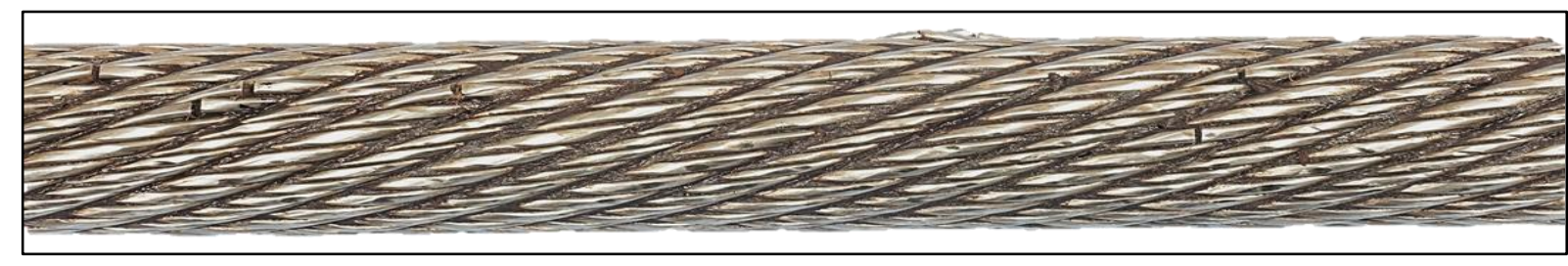

Figure 8: Steel wire rope with broken inner wires 


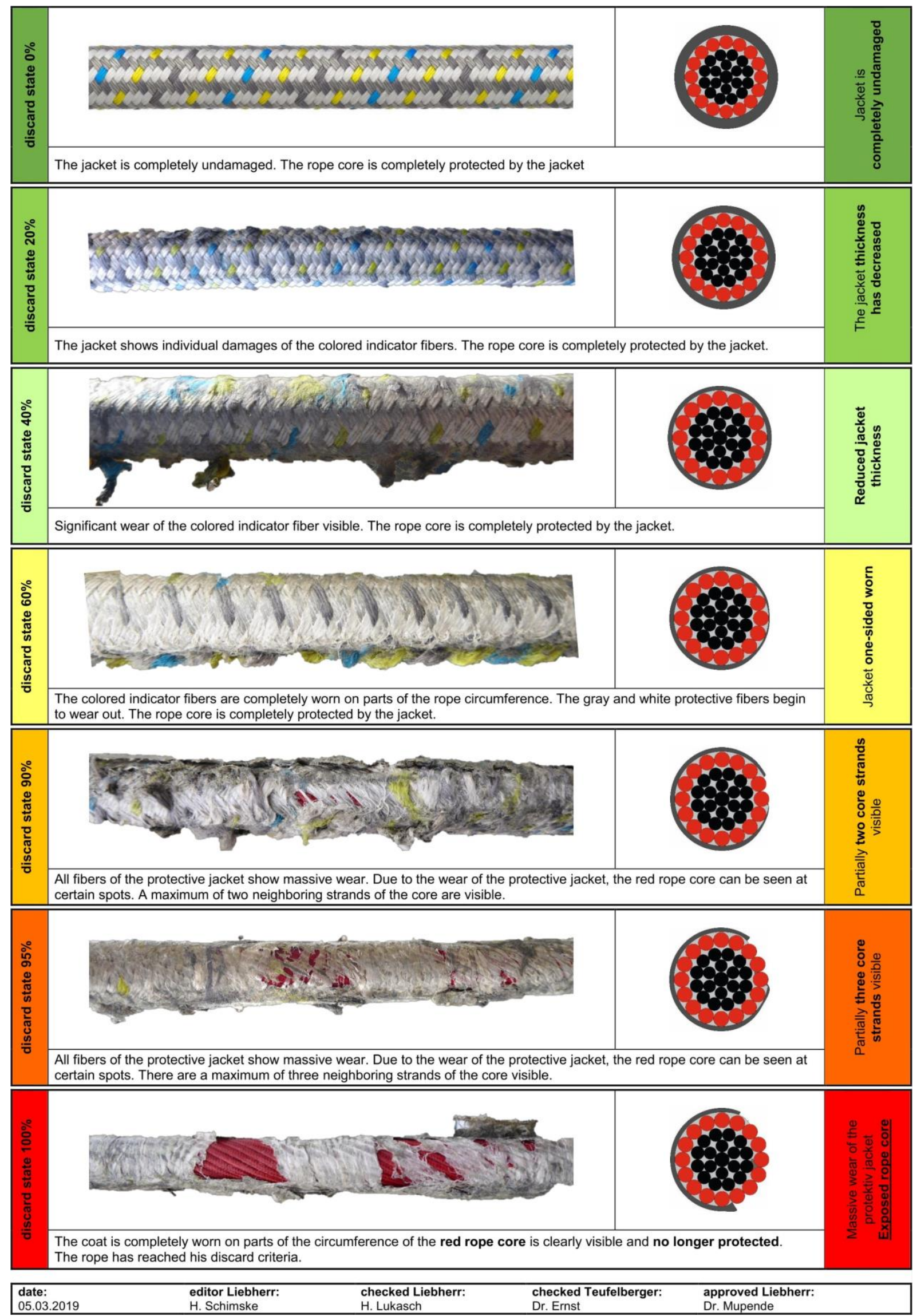

Figure 9: Degree of damage and discard criteria for detection of multilayer wound fiber ropes 
Liebherr and Teufelberger designed an easy and safe discard system, which uses different wear resistant fibre types in the rope jacket, see Figure 9. As soon as the red indicator fibres of the core are visible, the rope has reached the point of discard. The wear resistance of the fibres in the jacket is calibrated onto the rope lifetime to show the point of discard at approximately $40 \%$ of the total lifetime until breakage. At the point of discard, the static safety factor must be higher than 3 . The soLITE discard recognition system meets the requirements of the fibre rope standards FEM 5.024 [3] and ISO 23624 [4].

\section{Conclusion}

With the new fibre rope, Liebherr and Teufelberger have opened a new chapter in the history of running ropes. For the first time the potential of high performance polymer fibres is used in hoist ropes. The new technology shows a direct increase in lifting capabilities of modern crane systems. Reduced dead weights of rope and hook block are decreasing the overall energy consumption of the crane. Also, the controls to determine the discard state of the rope are eased by simply looking out for the red colour indication. The lightweight rope eases the crane build up process and contamination of the crane due to spilled rope grease is a problem of the past. The increased lifetime of the rope on the crane by up to factor 4 extends the crane availability and shows the sustainability of the new technology.

In the current development project, the rope drive, the rope fabrication process and the discard system for the 20 and $22 \mathrm{~mm}$ ropes was developed. These ropes are working in multi-layer spooling up to 5 layers in series. For the future, the development will focus on bigger diameters especially on the fabrication process to provide a fibre ropes with a high lateral stiffness as a basis when winding up to 11 layers.

\section{References}

[1] Teufelberger Fiber Rope GmbH: soLITE® - The high strength fiber rope for challenging lifting applications, brochure, 2019

[2] European patent Office: Seiltrommel und Seilrolle für Faserseiltriebe, EP 2668129 B1, (2015)

[3] VDMA-Verlag: Guideline - Safe Use of High Performance Fibre Ropes in Mobile Crane Applications, FEM 5.024, 2017

[4] International Organization for Standardization: Safe Use of High Performance - Fibre ropes in Crane applications, ISO/CD TS 23624

[5] K. -. Wehking, K. Feyrer, A. Klöpfer, D. Moll, R. Verreet, W. Vogel, S. Winter: Laufende Seile - Bemessung und Überwachung, Expert Verlag, 2018

[6] G. Novak: Dissertation: Zur Abschätzung der Lebensdauer von laufenden hochmodularen Faserseilen, IFT - Universität Stuttgart, 2017

[7] T. Heinze: Dissertation: Zug- und biegewechselbeanspruchte Seilgeflechte aus hochfesten Polymerfasern, TU Chemnitz, 2013

[8] M. Wehr: Dissertation: Beitrag zur Untersuchung von hochfesten synthetischen Faserseilen unter hochdynamischer Beanspruchung, IFT - Universität Stuttgart, 2017

[9] Liebherr-Werk Biberach GmbH: Fibre-Cranes - The lightness of power, brochure, 2020

[10] Beuth Verlag, Krane - Drahtseile - Wartung und Instandhaltung, Inspektion und Ablage, ISO 4309, 2010 